\title{
Effect of manganese sulphide particle shape on the retardation of grain boundary motion
}

\author{
L. Guo ${ }^{\mathrm{a}, *}$, H. Roelofs ${ }^{\mathrm{b}}$, M. I. Lembke ${ }^{\mathrm{c}}$, H. K. D. H. Bhadeshia ${ }^{\mathrm{a}}$ \\ ${ }^{a}$ Department of Materials Science and Metallurgy, University of Cambridge, 27 Charles Babbage Road, \\ Cambridge CB3 OFS, U.K. \\ ${ }^{b}$ R\& D, Swiss Steel AG, Emmenweidstr. 90, CH-6020 Emmenbrücke, Switzerland \\ ${ }^{c}$ Steeltec AG, Emmenweidstr. 72, CH-6020 Emmenbrücke, Switzerland
}

\begin{abstract}
The pinning of grain boundaries by manganese sulphide particles is examined experimentally as a function of the shape and size of the inclusions. This is in the context of free-machining steels that rely on the sulphide particles to break machining debris into chips in order to make the machining process efficient while at the same time enabling a good surface finish. Nevertheless, the particles can have other consequences, such as on the development of microstructure during cooling from the fabrication temperature. Extremely long MnS particles are found to be more effective at hindering the motion of grain boundaries than those that approximate spherical shape.
\end{abstract}

Keywords: Zener drag, MnS, Grain boundary, Austenite, Free-machining steel

\section{Introduction}

Free-machining steels often are designed to contain a number of manganese sulphide inclusions. Their role in improving machinability is complex, but in simple terms, they influence the adhesion of the steel to the tool and enable chip-breaking [1, 2]. However, their presence has other consequences, for example in the development of the austenite grain structure and hence its subsequent transformation characteristics.

The effect of inclusions on grain growth, i.e. on grain boundary motion, was described by Smith [3] who argued that small particles could hinder the motion and that it did not require the formation of continuous boundary-films of some phase to immobilise the boundaries. Zener provided Smith with an estimate of the restraining effect of a spherical particle on a grain boundary [4], so the interaction of particles with boundaries has since then been referred to as Zener drag. The assumption of a spherical inclusion shape is common $[3,5,6,7]$, but in some cases a consideration of anisotropic shapes becomes important. Nes and co-workers [8] studied the pinning of grain boundaries by ellipsoidal particles to find that particle shape and distribution are important factors in Zener drag. This orientation assumption was further relaxed by Li and Easterling who studied ellipsoidal particles with different axial ratios and

\footnotetext{
${ }^{*}$ Corresponding author

Email address: lg446@cam.ac.uk, lei-guo@outlook.com (L. Guo)
} 
orientations with respect to the grain boundary [9]. They concluded that an elongated particle is particularly effective when oriented the long axis is parallel to the grain boundary with a dependence on the exact particle shape. However, these studies are mostly theoretical $[8,10,11,12,13]$ with sparse experimental evidence.

In high sulphur free-machining steels, the MnS particles are usually quite large and very long in hot rolled bars, a few micrometres in diameter and length ranging from $10 \mu \mathrm{m}$ to millimetres. The purpose of the work presented here was to reveal the role of the particles in determining the austenite grain structure in the context of other work focused on predicting the transformation charcteristics of such alloys [14, 15].

\section{Experimental details}

A commercial free-machining steel in the hot-rolled condition was supplied by Swiss Steel $\mathrm{AG}$ in the form of rods $32 \mathrm{~mm}$ in diameter, with the chemical composition as listed in Table 1. The MnS particles which precipitate from liquid during solidification are elongated hot processing in the rolling direction (Fig. 1a).

Test samples $8 \mathrm{~mm}$ in diameter and $10 \mathrm{~mm}$ long were prepared from the hot-rolled bar. One group of these samples was "homogenised" at $1200^{\circ} \mathrm{C}$ for $48 \mathrm{~h}$ in a vacuum furnace, for comparison against the remaining sampes that were left in the manufactured condition. The purpose of the homogenisation was to break down the elongated MnS particles into smaller ones in a manner akin to the instabilities that occur in fluid streams, and to induce some spheroidisation as illustrated in Fig. 1b.

The austenite grain size as defined by the mean lineal intercept $\bar{L}_{\gamma}$, was naturally much greater frollowing the homogenisation treatment when compared with the as-received state. To introduce a uniform and comparable $\gamma$-grain size, all samples were heat-treated in a THERMECMASTOR-Z thermomechanical simulator with a vacuum of around $10^{-3} \mathrm{~Pa}$. To facilitate a clear charcterisation of the austenite grain size, the cylindrical samples had flats polished along their lengths so that any thermal grooving at the austenite grain boundaries can be used to measure the grain size; the details are described in [16]. The treatments implemented in the simulator involved heating up to austenitisation temperature of $1000^{\circ} \mathrm{C}$, $1100{ }^{\circ} \mathrm{C}$ or $1200^{\circ} \mathrm{C}$ at a rate of $5^{\circ} \mathrm{C} \mathrm{s}^{-1}$, holding for $5 \mathrm{~min}$, followed by natural cooling inside the vaccum chamber to ambient temperature.

The austenite grain size was measured using the mean linear intercept method and is shown in Fig. 2a. The reaustenitisation at $1085^{\circ} \mathrm{C}$ for $5 \mathrm{~min}$ of the homogenised sample led to approximately the same austenite grain size as the as-received sample reaustenitised at $1200^{\circ} \mathrm{C}$ for $5 \mathrm{~min}$, with a mean linear intercept of $50 \mu \mathrm{m}$. So all samples were reaustenitised at $1085^{\circ} \mathrm{C}$ for $5 \mathrm{~min}$ for the homogenised group, and at $1200{ }^{\circ} \mathrm{C}$ for $5 \mathrm{~min}$ for the as-received group, respectively. The samples with the same grain size were once again reaustenitised at $1000^{\circ} \mathrm{C}, 1100{ }^{\circ} \mathrm{C}$ or $1200{ }^{\circ} \mathrm{C}$ for $5 \mathrm{~min}$, respectively. Their austenite grain sizes were measured and are presented in Fig. 2b. The size $\bar{L}_{\gamma}$ of the homogenised sample remained significantly greater than the as-received ones.

Synchrotron X-ray diffraction was used to examine the presence of any other precipitates or inclusions in the steel, the diffraction patterns from $3 \mathrm{~mm}$ diameter rod samples were collected by a Perkin Elmer XRD 1621 flat panel detector in the Deutsches Elektronen- 
Synchrotron (DESY) P07 beamline, with beam energy of $100 \mathrm{keV}$, spot size of $1 \mathrm{~mm} \times 1 \mathrm{~mm}$ and sample to detector distance of $1.280 \mathrm{~m}$.
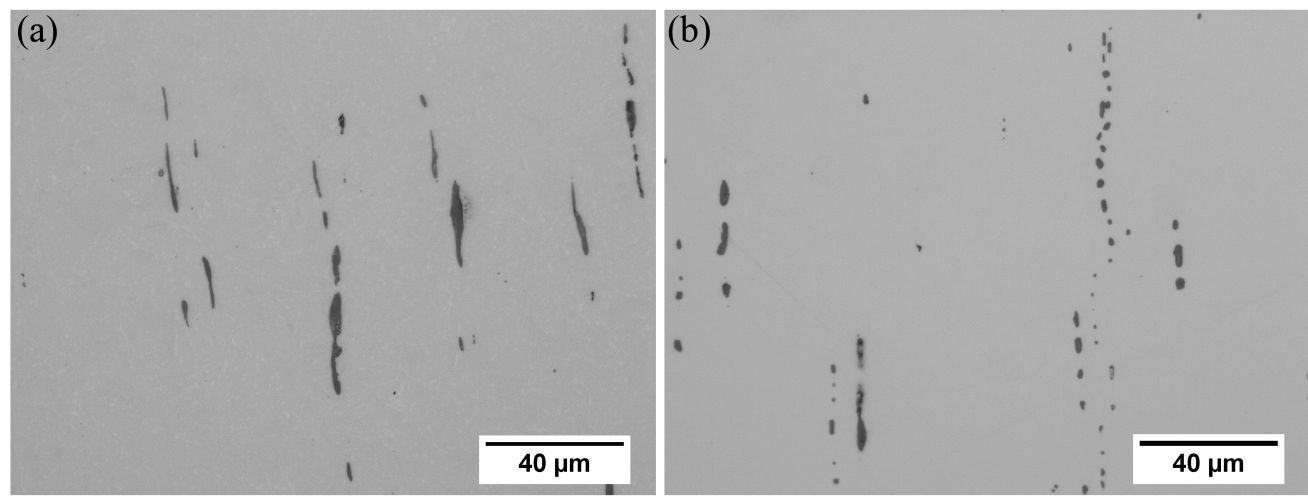

Figure 1: (a) MnS particles in the rolling direction of the as-received sample. (b) Fragmented MnS particles in the rolling direction after homogenisation at $1200^{\circ} \mathrm{C}$ for $48 \mathrm{~h}$.
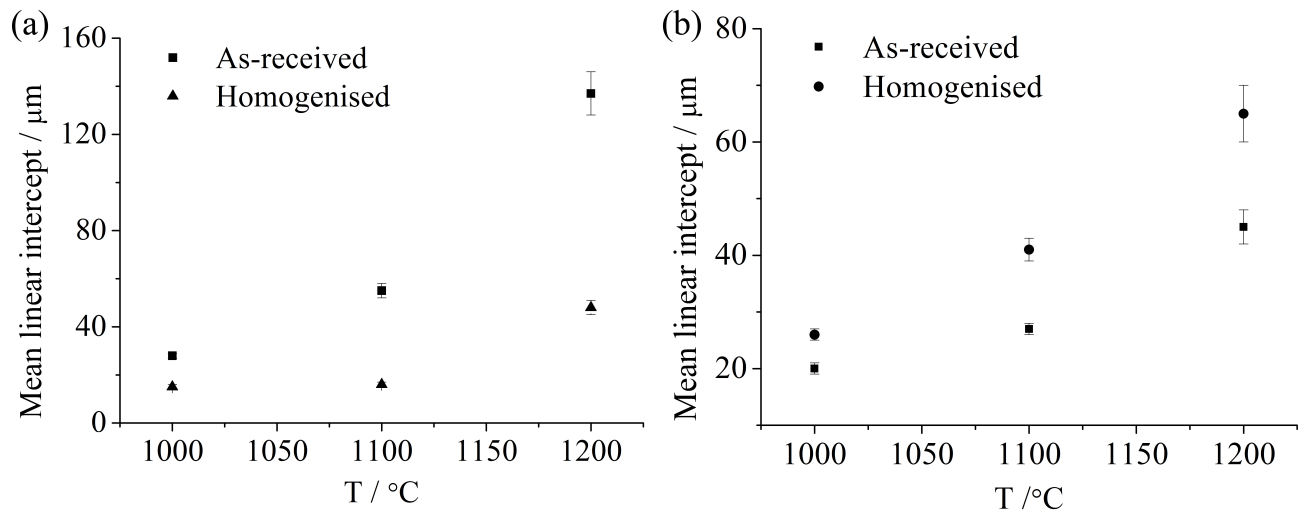

Figure 2: (a) Austenite grain size as a function of reaustenitisation temperature. (b)Austenite grain size as a function of reaustenitisation temperature for samples with the same starting microstructure and austenite grain size. As-received samples were reaustenitised at $1200^{\circ} \mathrm{C}$ for $5 \mathrm{~min}$ cooled to room temperature (RT), and reaustenitised once again at $1000^{\circ} \mathrm{C}, 1100^{\circ} \mathrm{C}$ or $1200^{\circ} \mathrm{C}$ for $5 \mathrm{~min}$, while the homogenised samples were reaustenitised at $1085^{\circ} \mathrm{C}$ for $5 \mathrm{~min}$ cooled to ambient temperature, and reaustenitised again at $1000^{\circ} \mathrm{C}$, $1100{ }^{\circ} \mathrm{C}$ or $1200^{\circ} \mathrm{C}$ for $5 \mathrm{~min}$. In these graphs, join the points using straight lines and then instead of having a key, put labels along the lines so that it is immediately obvious what each bit refers to.

Table 1: Chemical composition (wt\%) of the studied steel

\begin{tabular}{ccccccccc}
\hline $\mathrm{C}$ & $\mathrm{Si}$ & $\mathrm{Mn}$ & $\mathrm{Ni}$ & $\mathrm{Mo}$ & $\mathrm{Cr}$ & $\mathrm{Cu}$ & $\mathrm{N}$ & $\mathrm{S}$ \\
0.22 & 0.97 & 1.53 & 0.18 & 0.14 & 1.54 & 0.17 & 0.0104 & 0.14 \\
\hline
\end{tabular}

There is a confusion of experimental results being mixed with experimental details, whereas features such as micrographs and graphs should be in the results section 


\section{Result and discussion}

There is a possibility that aluminium nitride, introduced during steel making, can hinder austenite grain growth at elevated temperatures $[17,18,16]$. The homogenisation treatment may lead to the dissolution of the AlN and hence explain why after homogenisation and reaustenitisation, $\bar{L}_{\gamma}$ remains greater than the samples that were reaustenitised from the asreceived condition. In other words, the re-precipitation of AlN in a manner conducive to Zener drag. What was the cooling rate? homogenisation should induce the AlN to precipitate, but syncrhotrohomogenisation treatment was very slow, so AlN should have precipitated. Previous work using synchrotron X-rays clearly revealed the AlN [16] so the samep method was applied to the present steel. Fig. 3 shows that AlN could not be detected in the asreceived steel, consistent with the very low concentrations present. Another explanation of the data in Fig. 2 is that homogenisation causes the large MnS particles to grow at the expense of smaller ones by Ostwald ripening, but in fact, the number density of particles increases as elongated sulphides split into arrays of smaller particles (Fig. 1). The real reason for the discrepancies following reaustenitisation of the homogenised and as-received samples may be associated with the different shapes of $\mathrm{MnS}$ particles in the two groups of specimens.

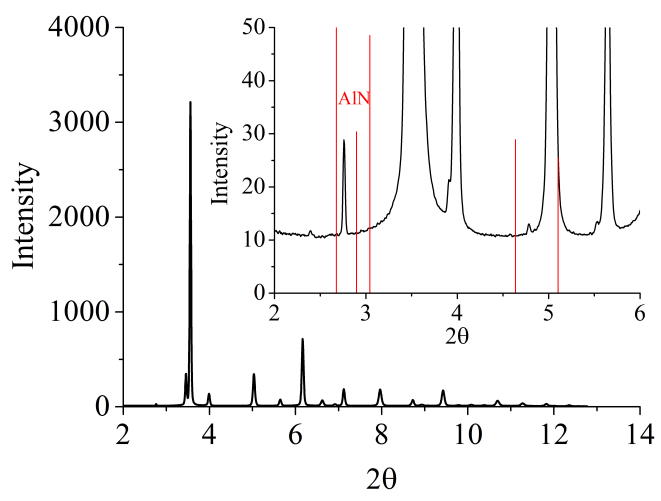

Figure 3: Synchrotron X-ray diffraction pattern of the as-received steel. The inset is a magnified portion of the spectrum where AlN major peaks should be with the five strongest peaks of AlN superimposed on, the heights of the five peaks are proportional to their theoretical intensities.

The resistance from a particle on the motion of grain boundary is proportional to the length of the intersection line. Previous theory has assumed that the particles are spherical. When the boundary first comes into contact, it will be attracted to the particle, due to the need to balance the interface tensions. It is only when the boundary has passed the maximum radius and attempts to move away from the particle, then a drag force is exerted to hold it back. The maximum pinning force $F_{\mathrm{s}}$ due to a single spherical particle is given by

$$
F_{\mathrm{s}}=\pi r_{\mathrm{s}} \sigma
$$

where $r_{\mathrm{s}}$ is the radius of the particle, $\sigma$ is the grain boundary energy per unit area.

When the rod-shaped particle is very long compared to the austenite grain, the segment of grain boundary which is in contact with the particle is held by the particle, as shown in 
Fig. 4a, which means the rod lies in the plane of the boundary as illustrated in Fig. 4b. The pinning force produced by this rod particle is

$$
f_{\text {rod }}=2 \sigma l_{\text {rod }} \cos \varphi=4 \sigma r_{\text {rod }} a \cos \varphi
$$

where $\varphi$ is the angle illustrated in Fig. $4 \mathrm{c}, l_{\text {rod }}$ is the length of the rod, $r_{\text {rod }}$ is the radius of the rod and $a=\frac{l_{\text {rod }}}{2 r_{\text {rod }}}$ is the aspect ratio of the rod. The maximum drag force is

$$
F_{\text {rod }}=4 \sigma r_{\text {rod }} a
$$

The radius of a sphere with equal volume is $r_{\mathrm{s}}=\left(\frac{3}{2} a\right)^{\frac{1}{3}} r_{\text {rod }}$, so the drag force of a spherical particle with equivalent volume is given by

$$
f_{\mathrm{s}}=2 \pi \sigma r_{\mathrm{s}} \sin \varphi \cos \varphi=2 \pi \sigma r_{\text {rod }}\left(\frac{3}{2} a\right)^{\frac{1}{3}} \sin \varphi \cos \varphi
$$

with the maximum drag force given by

$$
F_{\mathrm{s}}=\pi \sigma r_{\text {rod }}\left(\frac{3}{2} a\right)^{\frac{1}{3}}
$$

Therefore, the ratio of maximum drag force of a rod over that of the sphere of identical volume is

$$
\frac{F_{\text {rod }}}{F_{\mathrm{s}}}=\frac{4}{\pi}\left(\frac{2}{3}\right)^{\frac{1}{3}} a^{\frac{2}{3}}
$$

If the rod now breaks into $n$ identical spherical particles spread evenly in the same length of the rod, the radius of each sphere is $r_{\mathrm{s}}^{\prime}=\sqrt[3]{3 a / 2 n} \times r_{\text {rod }}$, the ratio of the drag force of a rod over the total drag force of the $n$ spherical particles is

$$
\frac{F_{\mathrm{rod}}}{F_{\mathrm{s}}^{\prime}}=\frac{4}{\pi}\left(\frac{2}{3}\right)^{\frac{1}{3}}\left(\frac{a}{n}\right)^{\frac{2}{3}}
$$

The calculated ratio of pinning force of a long rod over $n$ spheres whose total volume is the same as the rod is shown in Fig. 5. The ratio of maximum pinning force of a rod over the $n$ spheres increases with the increase of aspect ratio, but decrease with the increase of $n$. For the average aspect ratio of 6 of the MnS particles found in this steel, if one rod particle breaks into 7 identical spheres spread evenly along the length of the rod, the pinning force of the rod is still larger than that of all the 7 spheres combined. Furthermore, a string of particles can be overcome by the the motion of individual grain boundary segments, in contrast to the big elongated particles that cannot be passed by the grain boundary in that fashion, so the calculations above may be conservative in representing the efficacy of the rod-shaped sulphide.

For the same volume fraction and number density of particles, different shapes can also change the probability of a a particle intersecting a grain boundary. As the surface which is not facing the moving boundary induces a drag force, half of the precipitate surfaces will 
drag the boundary, and as the net interaction area increases so does the drag force. As the total precipitate surface area is depending on its shape, sphere has the smallest surface area per unit volume, so it should be the least effective, which is in agreement with the work of et al. [11], who found cubic particles to be more effective than spherical ones, and more recently, Chang et al. [12] found needle-shaped particle to be more effective than spherical ones, and that the orientation of the needles in the sample had a small effect on pinning.

(a)
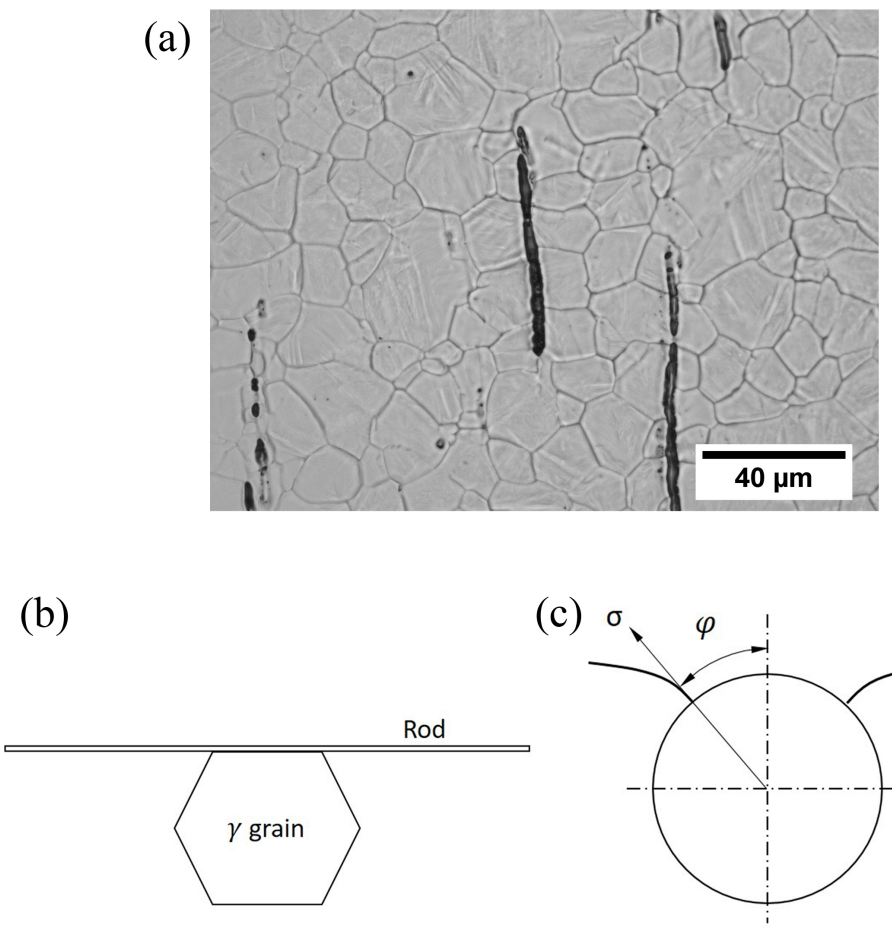

(c)

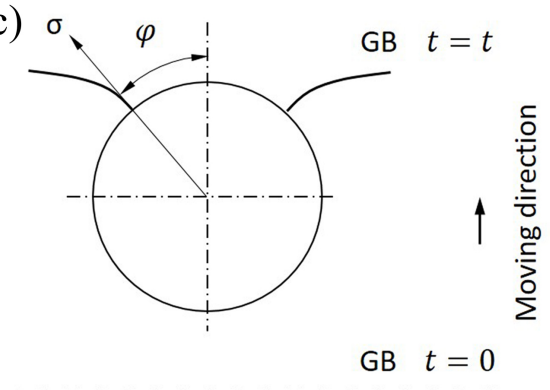

Figure 4: (a) Large long particles blocking sideways grain growth. (b) Schematic illustration of interaction between a long particle and an austenite grain boundary. (c) Side-view of the rod and the boundary with the parameters used in the model. 


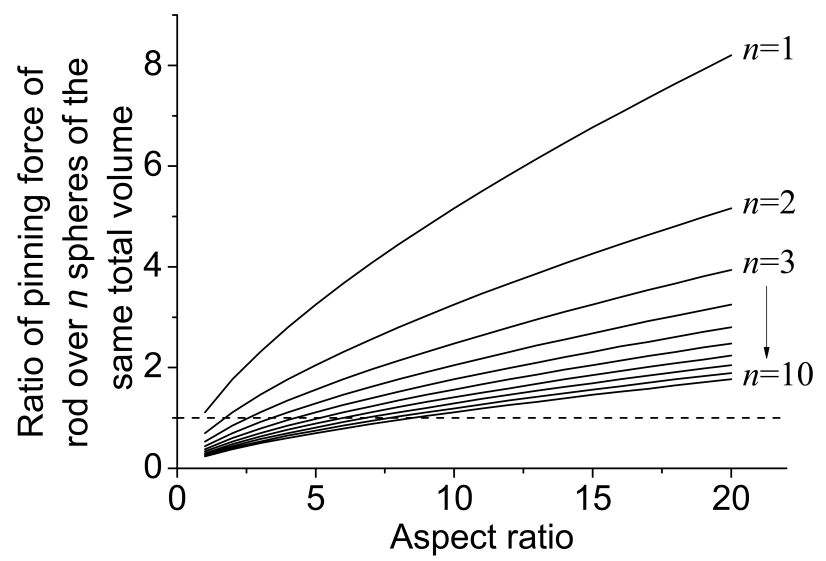

Figure 5: Calculated ratio of maximum drag force of a rod particle over $n$ spherical ones with the same total volume. The horizontal dashed line indicate the equal pinning force.

\section{Conclusions}

1. High-sulphur free-machining steels contain manganese sulphides, some of which are rod-shaped with lengths that span may austenite grains. The rods can be induced to break up into arrays of spherical particles by heat treatment at elevated temperatures, a process presumably driven by the minimisation of total interfacial energy. However, unlike coarsening reactions where the same driving force operates, the number density of particles increases due to the fragmentation of the rods into spheres.

2. The ratio of the Zener drag force due to long rod-shaped particles, to that of a series of $n$ spheres that result from the fragmentation of a rod, is proportional to $\sqrt[2]{a / n}$, where $a$ is the rod aspect-ratio. It follows that there are circumstances in which the influence of rods can be greater or less than that of spheres, as illustrated in Fig 5.

3. For the steel studied here, an elevated temperature 'homogenisation' heat treatment leads to an irreversible change in MnS morphology and number density. The effect is to reduce the Zener drag force so that the austenite grain size obtained during reaustenitisation following this homogenisation is always greater than the case where the homogenisation heat treatment is omitted.

4. For the steel studied here, it has been verified using synchrotron X-rays that aluminium nitride cannot be detected and hence does not play a role in influencing the development of the austenite grain structure. This is in contrast to a pressure vessel steel where the same technique revealed the nitride and grain growth data indicated a large increase in the rate of grain growth when the nitride was dissolved by heat treatment.

\section{References}

[1] M. E. Merchant, N. Zlatin, Basic reasons for good machinability of free machining steels, Transactions of the American Society for Metals 41 (1949) 647-677.

[2] H. Yaguchi, Scanning electron microscopy and electron microprobe analysis of built-up edges in low carbon resulfurized free-machining steel, Materials Science \& Engineering (1986) L27-L30. 
[3] C. S. Smith, Grains, phases and interfaces: an interpretation of microstructure, Metals Technology 15 (1948) 1-37.

[4] M. Hillert, Zener's pinning effect: role of dispersed particle on grain size, Tech. Rep. TRITA-MAC-0369, Royal Institute of Technology, Stockholm, Sweden (1988).

[5] P. A. Manohar, M. Ferry, T. Chandra, Five decades of the Zener equation, ISIJ international 38 (1998) 913-924.

[6] B. N. Kim, T. Kishi, Finite element simulation of Zener pinning behavior, Acta materialia 47 (1999) 2293-2301.

[7] G. Gottstein, L. S. Shvindlerman, On the retardation of grain boundary motion by small particles, Scripta Materialia 63 (2010) 1089-1091.

[8] E. Nes, N. Ryum, . Hunderi, On the zener drag, Acta Metallurgica 33 (1985) 11-22.

[9] W. B. Li, K. E. Easterling, The influence of particle shape on Zener drag, Acta Metallurgica et Materialia 38 (1990) 1045-1052.

[10] C. Li, A. J. Freeman, H. J. F. Jansen, C. L. Fu, Magnetic anisotropy in low-dimensional ferromagnetic systems: Fe monolayers on $\mathrm{Ag}$ (001), $\mathrm{Au}(001)$ and $\operatorname{Pd}(001)$ substrates, Physical Review B 42 (1990) 5433-5422.

[11] S. P. Ringer, W. B. Li, K. E. Easterling, On the interaction and pinning of grain boundaries by cubic shaped precipitate particles, Acta Metallurgica 37 (1989) 831-841.

[12] K. Chang, W. Feng, L. Q. Chen, Effect of second-phase particle morphology on grain growth kinetics, Acta Materialia 57 (2009) 5229-5236.

[13] K. Chang, L. Q. Chen, Quantitative evaluation of particle pinning force on a grain boundary using the phase-field method, Modelling and Simulation in Materials Science and Engineering 20 (2012) 055004.

[14] J. Chen, H. K. D. H. Bhadeshia, S. Hasler, H. Roelofs, U. Ulrau, Complete calculation of steel microstructure for strong alloys, in: T. Pérez (Ed.), New Developments on Metallurgy and Applications of High Strength Steels, Buenos Aires, Vol. 2, TMS-AIME, Materials Park, Ohio, USA, 2008, pp. 749-759.

[15] H. Roelofs, S. Hasler, L. Chabbi, U. Urlau, J. Chen, H. K. D. H. Bhadeshia, Multiphase structures in case hardening steels following continuous cooling, in: T. Perez (Ed.), New Developments on Metallurgy and Applications of High Strength Steels,, TMS-AIME, Materials Park, Ohio, USA, 2008, pp. 761-768.

[16] H. Pous-Romero, I. Lonardelli, D. Cogswell, H. K. D. H. Bhadeshia, Austenite grain growth in a nuclear pressure vessel steel, Materials Science \& Engineering A 567 (2013) $72-79$. 
[17] T. Gladman, F. B. Pickering, Grain coarsening of austenite, Journal of the Iron and Steel Institute 205 (1967) 653-664.

[18] M. Militzer, A. Gumelli, E. B. Hawbolt, T. R. Meadowcroft, Austenite grain growth kinetics in Al-killed plain carbon steels, Metallurgical and Materials Transactions A 27A (1996) 3399-3496. 